\title{
Nurses' Knowledge And Performance About Physical Restraints For Critical Ill Patients
}

\author{
Mohammed M. AL-gabri, Osama A. Mohammed, Mogedda M. Mehany \& Mona A Mohammed \\ Demonstrator Critical Care Nursing, Department of Nursing, University of Thamar, Yemen. \\ Professor of Anesthesia \& ICU, Faculty of Medicine, Assiut University Egypt. \\ Lecture, Critical Care Nursing, Faculty of Nursing, Assiut University Egypt. \\ Professor, Critical Care Nursing, Faculty of Nursing, Assiut University Egypt.
}

\begin{abstract}
Physical restraint is often seen as a simple solution to maintain patient comfort and safety in the intensive care unit, physical restraint is always accompanied by risk of complication Preventing and protecting the patient from harm are central nursing responsibilities for individuals who are temporarily incapacitated. Aims of study assess the Nurses' Knowledge and Performance about Physical Restraints in Critical ill Patients. (Design) The descriptive research design. (Setting) This study was carried out in the Trauma Intensive Care Unit at Assiut University Hospitals. (Sample) The sample of this study was consisted of 60 nurses. (Tools) two main tools used in this study. Tool I: Physical Restraints knowledge questionnaire. Tool II Observational checklist Tool. Main results the current study demonstrated that the majority of the study sample (70\%) was having a satisfactory level of knowledge in all items, and more than half of nurses (68.3\%) had an unsatisfactory level of Performance in all items. There were statically significant differences between years' experience, qualification and nurses' knowledge, nurses' performance of the trauma intensive care unit. Recommendation Provide training programs to update critical care nurses' knowledge and performance about new physical restraint. Booklets about physical restraint should be available in each department, ICU.
\end{abstract}

Key words: Physical Restraint, Nurses, Knowledge, Performance \& Critically ill Patients.

\section{Introduction}

Individuals who are admitted to an intensive care unit (ICU) who are bedridden, disoriented and agitated are a group with a particular need for protection and safety. One of the methods used to ensure patients' safety in health care institutions is the use of physical restraints. Physical restraint is defined as a physical or mechanical tool tied to a patient's body or the use of physical strength of health care personnel for a short period of time with patients to limit patient's movements or to prevent the patient from moving easily study done by (Eşer*, \& Hakverdioğlu, 2007and Fariña-López et al., 2014 \& Milisen, 2009) According to the Royal College of Nursing(Gallagher, 2009). There is no precise legal definition of restraint; however, 'in broad terms, it means restricting someone's liberty or preventing them from doing something they want to do.(Hine, 2007).

Restraint in medicine is the use of physical Restraint to control unwanted behavior, such as agitation, selfintubation, and unwilling removal of invasive devices or fall. The major reason for the use of physical restraints in intensive care units (ICUs)is to protect patients from self-removal of therapeutic devices in light of the current sedation trends including daily wakening protocols and a shift in clinical patient management from deeper to lighter sedation.(Facolt et al., 2011, Yves Matillon, 2011)
Physical restraint includes vests, straps/belts, limb ties, wheelchair bars and brakes, chairs that tip backwards, tucking in sheets too tightly, and bedside rails.(Gastmans \& Milisen 2006)

The prevalence of restraint use reported in the literature, ranges between $15 \%$ and $66 \%$ in Critical ill Patients and between $8 \%$ and $68 \%$ in hospital settings. (Gulpers et al., 2012; Hamers \& Huizing 2005, Coyne \& Scott 2014)In Egypt, physical restraint is a more conventional practice in ICUs. There are no available guidelines or legal regulations concerning physical restraint use. Most nursing research in Egypt focuses on educational programs for nurses, surveying nurses' views about certain aspects of care, and quasi-experimental studies.(Kandeel \& Attia, 2013)

Physical restraint is always accompanied by risk of complications. These complications may be serious and life-threatening. (Demir, 2007)Physical restraining has negative implications as well. The implications include: injuries, ulcers, respiratory complications, reduced activities of daily living (ADL), muscle atrophy, increased anxiety and increased risk of mortality.(Ben Natan et al., 2010). Preventing and protecting the patient from harm are central nursing responsibilities for individuals who are temporarily incapacitated.(Azab et al., 2013) Also, the must perfermen Continuous monitoring of 
physical health status (e.g. Skin color, extremity movement and sensation) and personal needs (e.g. Toileting, food and fluids). Maximum protection of privacy and optimizing psychosocial comfort Interruption of physical restraints at regular intervals Re-evaluate the justification for physical restraint at regular intervals (Möhler at al., 2012).

The nurse must identify reason for using a restraint Type of restraint Explanation given to client and family .Date and time of and client's response to application Length of time restraint used. Frequency of monitoring and client's response Safety (release from the restraint along with periodic, routine exercise and assessment for circulation and skin integrity) Assessment for continued need of restraint Outcome of restraint use.(Lois White, Gena Duncan, 2011).

\section{Significance of the study}

According to the annual record of assuit Hospital, University 348 of patients were admitted to the trauma intensive care unit during the year of 2012. And the numbers of the beds in the unit are nineteen beds (Assuit University Hospital, 2012)

Physical restraints are highly preferred practice in intensive care units. Most of the nurses prefer restraining patients due to increase their workload in addition to increasing security, preventing patients from falling down from hospital beds or preventing dislodgement of medical equipment.

There are many policies on physical restrain in intensive care units in Assiut University hospitals and I have not had an adequate opportunity for the intensive care nurses on how to learn and apply them correctly, this is the first study in this area will contribute to the little existing about knowledge and practice of critical nurses about physical restraints that will be important to develop a restraint policy and educate nurses to implement in Egyptian ICUs.

\section{Aims of the study}

The aim of this study was to assess nurses' knowledge \& performance about physical restraints for critically ill patients.

\section{Research questions}

What is nurses' knowledge about physical restraints for critical ill patients?

What are nurses' performances about physical restraints for critical ill patients?

\section{Material \& Methods}

\section{Study design}

The descriptive research design was used to conduct this study.

\section{Study Setting}

The study was carried out in the Trauma Intensive Care Unit of Assuit University Hospital.

\section{Sample size}

All critical care nurses (60 nurses), working in the above mentioned setting, who apply physical restraints, were included in the present study.

\section{Study tools}

Two tools were utilized to collect data in this study includes:-

Tool (I): Physical Restraints knowledge questionnaire.

This tool was developed by the researcher based on reviewing of the relevant literature (Nettina \& Msn 2013) (Pamela Lynn, 2011a) and translated into Arabic language and used to assess the studied nurses' knowledge about physical restraints in trauma critical care unit; it includes two main parts as following.

\section{Part one: nurses' characteristic}

It includes nurses' characteristics, such as; code, marital status, years of experience in general nurses and trauma intensive care unit, qualification, attendance of previous training courses about physical restraints.

Part two: It includes questions to assess nurse's basic knowledge regarding physical restraining as definition, indications, alternatives, types, contraindications, complications, and barriers for use.(Bizek 2010),

-Tool II: Physical Restraints Observational checklist Tool:-

This tool was adapted from (Potter et al,2005) (Pamela Lynn, 2011b). It is used to assess nursing performance while applying and providing maintenance care of physical restraint. It contains four main sections covering the main steps of restraint use and care; patients' preparation, application, post care, and documentation. :-

Part one: - is for assessment which involves items to be assessed before the application of a physical restraint, such as; physician's order and the site of restraint, preparation of equipment, patient, and the environment

Part two: application of the physical restraint, including practices such as; padding bony prominences, and securing the restraint accurately.

Part three: involves post care practices such as washing hands, and performing regular care while the restraint is maintained finally.

Part four: is for documentation, which includes items such as documentation of the type, date application, location, duration, indications and unexpected outcomes for retraining. 


\section{Methods}

The study was conducted throughout two main phases:

\section{1- Preparatory phase}

- An Official permission from the faculty of nursing to conduct the study was delivered to the hospital authorities (head department of a trauma intensive care unit) in Assuit university hospital and approval to conduct this study was obtained.

Ethical considerations: the nature and purpose of the study were explained to every nurse

- Research proposal approved by Ethical committee in the faculty of nursing.

- There is no risk for study subject during application of the research.

- Written consent will be obtained from the nurses that are willing to participate in the study, after explaining the nature and purpose the study.

- The study will follow common ethical principles in clinical research.

- Confidentiality and anonymity will be assured.

- Study subject has the right to refuse to participate and or withdraw from the study without any rational any time.

- Study subject privacy will be considered during collection of data.

Content validity: The tools were tested for content validity by Jury of 5 expertise from the field of staff critical care ( 3 professors, medical and 1 assistant professor anesthesia) and (nursing educators 3 professors).

Reliability: Knowledge And Performance about Physical Restraints was established (cronbach's Alpha >70). Internal consistency reliability for observation checklist was established (Cronbach's Alpha <80).

A pilot study carried out before starting of data collection to test the feasibility and the clarity of the study tools on $10 \%$ of the sample, the analysis of pilot study define the modification required in the tool used, and the necessary modification was done prior to data collection. The studied subjects were excluded from the actual study.

\section{2- Implementation phase}

- Once permission was granted to proceed with proposed study, the researcher initiated data collection. At the initial interview the researcher introduced himself to initiate a line of communication, explain the nature \& purpose of the study prior to answering the questions to gain their consent \& cooperation and fill out the questionnaire sheet (Tool I) while nurses were on duty during any shift, each nurse was observed by the researcher by using observation checklist (Tool II) one time at any shift. While she was a performance nursing intervention Assessment physically restrained, Preparation of equipment, patient physical restraint, Application of the physical restraint, Post care practices, physical restraint, Documentation physical restraint. Nurses were observed until the restraint was removed or the patient was discharged from the ICU.

- The whole period for implementation of study started from January to April. (2014)

- Two methods were used for data collection by the researchers, including:-

- Nurses' knowledge was assessed by use questionnaire (Appendix I). The total number of questions was (12) items..

- As in tool I. The correct response is scored as "2" and incorrect response or do not know as " 1 ". The maximum score for the questionnaire was (25)degree.

- Scoring system knowledge

- Unsatisfactory $(<60 \%)$ poor practice

- Satisfactory $>60 \%$ )

- Direct observation of the nurses when giving nursing care to the patient regarding physically restrained by using Observational checklist (Appendix II)

- Observation checklist sheet included the following items:

- Assessment physically restrained included (10) items

- Preparation of equipment, patient physical restraint included (3) items

- Application of the physical restraint included (11) items

- Post care practices, physical restraint included (5) items

- Documentation physical restraint included (6) items

It included (80) degree.

The total score for this observation Performance checklist is 35 points, in which; each practice performed completely and accurately (2) point. Done incorrectly, incomplete (1) not done practice is graded as zero. The maximum possible score for the physical restraint check list is 80 .

Scoring system performance:

- Unsatisfactory $(<60 \%)$ poor practice

- Satisfactory $>60 \%$ )

Statistical analysis

All data were recorded in a special chart for every Nurse's. The collected data were coded, analyzed and tabulated. Data entry and analysis were done using SPSS 16.0 statistical software package. Data were presented using descriptive statistics in the form of frequencies and percentages for qualitative variables, means and standard deviations for quantitative variables. Quantitative continuous data were compared using analysis of variance test in case of 
comparisons between two independent groups using the chi - square test for non-parametric data to determine significant person correlation.

Statistically significant differences were considered when the P - value used as follows:-

$\mathrm{P}>0.05$ non-significant $\quad * \mathrm{P}<0.05$ significant

$* * \mathrm{P}<0.01$ moderate significant

$* * * \mathrm{P}<0.001$ highly significant.

\section{Results}

Table (1): - Socio-demographic characteristics of the study sample $(n=60)$.

\begin{tabular}{|c|c|c|}
\hline \multirow{2}{*}{ Variables } & \multicolumn{2}{|c|}{ I.C.U trauma $(\mathrm{N}=60)$} \\
\hline & $\mathbf{N}$ & $\%$ \\
\hline \multicolumn{3}{|l|}{ Marital status } \\
\hline -Single & 36 & 60.0 \\
\hline -Married & 24 & 40.0 \\
\hline \multicolumn{3}{|l|}{ 2- Nurses' qualification } \\
\hline - secondary nursing School & 18 & 30.0 \\
\hline - Technical Institute Diploma & 13 & 21.7 \\
\hline - B.Sc. Nurses & 29 & 48.3 \\
\hline \multicolumn{3}{|l|}{ 3- Years of experience in the nursing } \\
\hline$<5$ years of experience & 26 & 43.3 \\
\hline $5-10$ years of experience- & 20 & 33.3 \\
\hline $10+$ years of experience- & 14 & 23.3 \\
\hline \multicolumn{3}{|l|}{ 4-Years of experience at the ICU } \\
\hline$-<5$ years of experience & 30 & 50.0 \\
\hline $5-10$ years of experience- & 21 & 35.0 \\
\hline $10+$ years of experience- & 9 & 35.0 \\
\hline \multicolumn{3}{|c|}{ 5- attendance of previous training course } \\
\hline Yes & 0 & 00.0 \\
\hline No & 60 & 100.0 \\
\hline
\end{tabular}

Figure (1): Frequency distribution of the study sample in relation to assessment of Nurses' level of knowledge $(\mathrm{No}=60)$.

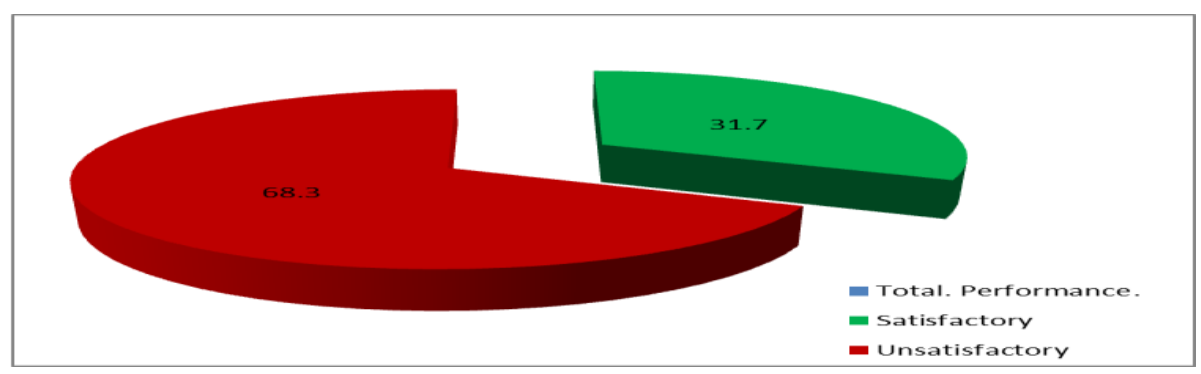

Figure (2): Frequency distribution of the study sample in relation to assessment of Nurses' level of Performance $(\mathrm{No}=60)$. 
Table (2): Frequency distribution of the Nurses' Knowledge I.C.U trauma (No=60).

\begin{tabular}{|l|c|c|}
\hline \multirow{2}{*}{\multicolumn{1}{|c|}{ Items of Nurses' Knowledge }} & \multicolumn{2}{c|}{ Nurses' Knowledge I.C.U trauma (N=60) } \\
\cline { 2 - 3 } & Total Score & Mean \pm Std. Deviation \\
\hline Definition of physical restraints. & 2 & $1.6333 \pm .78041$ \\
\hline Indication of physical restraints. & 2 & $1.5667 \pm .62073$ \\
\hline Alternatives of physical restraints. & 2 & $1.0667 \pm .79972$ \\
\hline Types of physical restraints. & 8 & $5.6500 \pm 1.11728$ \\
\hline Precautions of physical restraints. & 2 & $1.3167 \pm .65073$ \\
\hline Complication of physical restraints. & 3 & $1.6000 \pm .74105$ \\
\hline Barriers of physical restraints. & 2 & $1.0000 \pm .73646$ \\
\hline Recording\& duration & 4 & $2.8500 \pm .57711$ \\
\hline Follow up of physical restraints. & 25 & $16.6333 \pm 3.57471$ \\
\hline Total. Score. & \multicolumn{2}{|c|}{} \\
\hline
\end{tabular}

Table (3): Frequency distribution of the Nurses' Performance I.C.U trauma (No=60).

\begin{tabular}{|l|c|c|}
\hline \multirow{2}{*}{\multicolumn{1}{|c|}{ Items of Nurses' Performance }} & \multicolumn{2}{c|}{ Nurses' Performance I.C.U trauma (N=60) } \\
\cline { 2 - 3 } & Total Score & Mean \pm Std. Deviation \\
\hline Assessment of physical restraints. & 20 & $10.1667 \pm 3.75597$ \\
\hline Preparation of physical restraints. & 12 & $8.7167 \pm 2.09189$ \\
\hline Application of physical restraints. & 22 & $12.0000 \pm 3.03091$ \\
\hline Post. Care of physical restraints. & 14 & $9.9333 \pm 1.68610$ \\
\hline Documentation of physical restraints. & 12 & $0.6667 \pm 1.53674$ \\
\hline Total. Score. & 80 & $42.0833 \pm 9.10260$ \\
\hline
\end{tabular}

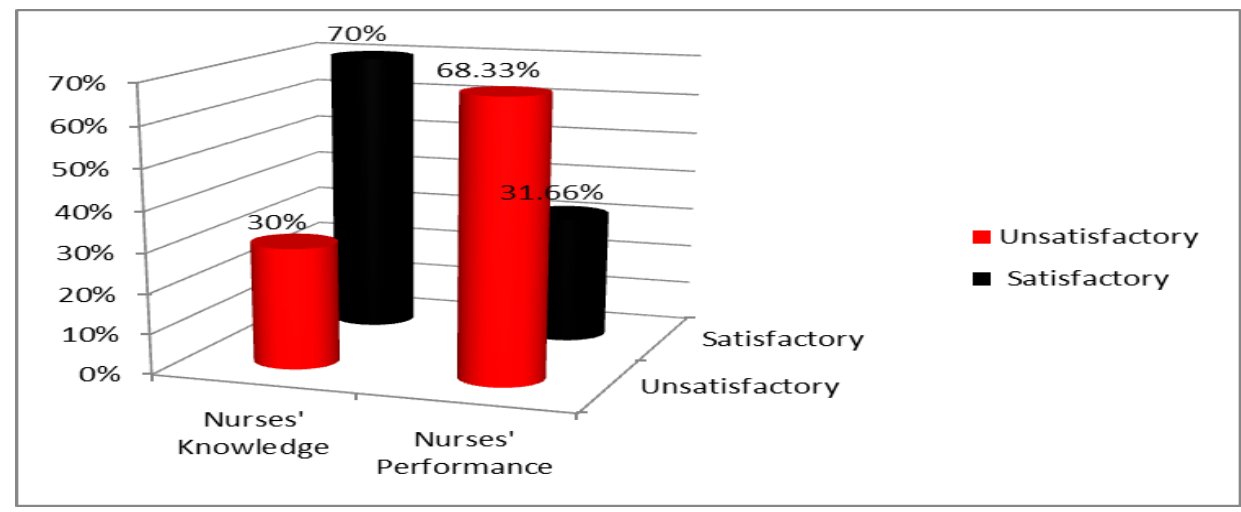

Figure (3) : state of Nurses' Knowledge and Performance among the study group (No=60).

Table (4): correlation between Nurses' Knowledge and Performance.

\begin{tabular}{|l|c|c|c|c|}
\hline Variables & N & Mean \pm Std. Deviation & Person correlation & P, value \\
\cline { 1 - 3 } Knowledge & 60 & $16.6333 \pm 3.57471$ & $0.55^{* *}$ & 0.05 \\
\hline Performance. & 60 & $42.0833 \pm 9.10260$ & \\
\hline
\end{tabular}
(N.B):- N.s ( $p>0.05)$ no significance
$* p<0.05$ significance

Table (5): correlation between Nurses' qualification and Nurses' Knowledge.

\begin{tabular}{|l|c|c|c|c|}
\hline \multicolumn{1}{|c|}{ Variables } & N & Mean \pm Std. Deviation & Person correlation & P, value \\
\hline Nurses' qualification & 60 & $2.1833 \pm .87317$ & \multirow{2}{*}{$0.35^{* *}$} & \multirow{2}{*}{0.06} \\
\hline Nurses' Knowledge & 60 & $16.6333 \pm 3.57471$ & & \\
\hline
\end{tabular}

(N.B):- N.s ( $p>0.05)$ no significance

$*^{* *} p<0.001$ moderate significance

$* p<0.05$ significance

$* * * p<0.0001$ high significance

Vol , (3) No , (5) June 2015 
Table (6): correlation between Years of experience at the I.C.U and Nurses' Knowledge.

\begin{tabular}{|c|c|c|c|c|}
\hline Variables & $\mathbf{N}$ & Mean \pm Std. Deviation & Person correlation & $P$, value \\
\hline Years of experience At the I.C.U & 60 & $1.6500 \pm .73242$ & \multirow{2}{*}{0.98} & \multirow{2}{*}{$0.02 *$} \\
\hline Nurses' Knowledge & 60 & $16.6333 \pm 3.57471$ & & \\
\hline $\begin{array}{l}(\boldsymbol{N} . \boldsymbol{B}):-N . s(p>0.05) \text { no significance } \\
* * p<0.001 \text { moderate significance }\end{array}$ & & $\begin{array}{l}* p<0.05 \text { significance } \\
* * * p<0.0001 \text { high sigl }\end{array}$ & ance & \\
\hline
\end{tabular}

Table (7): correlation between Nurses' qualification and Performance.

\begin{tabular}{|c|c|c|c|c|}
\hline Variables & $\mathbf{N}$ & Mean \pm Std. Deviation & Person correlation & P, value \\
\hline Nurses' qualification & 60 & $2.1833 \pm .87317$ & \multirow{2}{*}{$0.27 *$} & \multirow{2}{*}{$0.038 *$} \\
\hline Performance. & 60 & $42.0833 \pm 9.10260$ & & \\
\hline
\end{tabular}

(N.B):- N.s ( $p>0.05)$ no significance

$* p<0.05$ significance

Table (8) correlation between Years of experience at the I.C.U and Performance.

\begin{tabular}{|l|c|c|c|c|}
\hline \multicolumn{1}{|c|}{ Variables } & $\mathbf{N}$ & Mean \pm Std. Deviation & Person correlation & P, value \\
\hline \begin{tabular}{|l|c|c|c|}
\hline Years of \\
Experience at the I.C.U
\end{tabular} & 60 & $1.6500 \pm .73242$ & $0.24 *$ & $0.04 *$ \\
\hline Performance. & 60 & $42.0833 \pm 9.10260$ & 0.2 \\
\hline
\end{tabular}

(N.B):- N.s $(p>0.05)$ no significance

$* * p<0.001$ moderate significance

Table (1): this table show Frequency distribution of the study sample in relation to socio-demographic characteristics. Regarding to marital status, results revealed more than half of this was single, While the married patients were $(40.0 \%)$. Regarding to Nurses' qualification, results revealed more than half of the single, B.Sc. Nurses (48.3\%), While $(30.0 \%)$ of them were the Diploma secondary nursing school and $(21.7 \%)$ were Technical Institute of Nursing. Regarding Years of experience in the nursing and ICU that was found that high percent of the nurses < 5 years of experience $(26)(43.3 \%) \&(30)(50.0 \%)$ respectively, while those of $5-10$ years of experience were $(33.3 \% \& 35.0)$ respectively and

those of $10+$ years of experience $(23.3 \% \& 35.0)$ respectively. It's apparent from the table of the nurses have not attended any previous training in the area of Physical Restraint.

Figure (1): This table also show that majority of the nurses $(70 \%)$ had satisfactory. Level of nurses Knowledge regards total score, while (30\%) unsatisfactory Level total scores about physical restraint.

Figure (2): shows that the majority of the nurses (68.3\%) had unsatisfactory. Level of Nurses' Performance regards total score, while (31.7\%) satisfactory Level total scores regarding Nurses' Performance about physical restraint.
$* p<0.05$ significance

$* * * p<0.0001$ high significance
Table (2): this table show Frequency distribution of the Nurses' Knowledge I.C.U trauma: - it was apparent from this table $\mathrm{M} \pm \mathrm{SD}$ mean score of the items Nurses' Knowledge (Definition, Indication, Alternatives, Types of physical restraints, Precautions, Complication and Recording\& duration Follow up of physical restraints) were $(1.6333 \pm .78041, \quad 1.5667 \pm .62073, \quad 1.0667 \pm .79972$, $5.6500 \pm 1.11728, \quad 1.3167 \pm .65073, \quad 1.6000 \pm .74105$, $1.0000 \pm .73646$, and $2.8500 \pm .57711)$ respectively It was found also from this table that total $\mathrm{M} \pm \mathrm{SD}$ of Nurses' Knowledge was $(16.6333 \pm 3.57471)$

Table (3): this table show Frequency distribution of the Nurses' Performance I.C.U trauma: - it was apparent from this table $\mathrm{M} \pm \mathrm{SD}$ mean score of the items Nurses' Knowledge (Assessment of physical restraints, Preparation, Application, Post Care of physical restraints, and Documentation of physical restraints) were $(10.1667 \pm 3.75597,8.7167 \pm$ $2.09189,12.0000 \pm 3.03091,9.9333 \pm 1.68610$, and.6667 \pm 1.53674 ) respectively It was found also from this table that total $\mathrm{M} \pm \mathrm{SD}$ of Nurses' Performance was $(42.0833 \pm 9.10260)$

Figure (3): shows state of Nurses' Knowledge \& Performance. Regarding Nurses' Knowledge it was found this more than half level of satisfaction of nurses Knowledge. Regarding nurses' performance it was apparent from this figure that more than half of the nurses (68.33) were unsatisfactory. 
Table (4): shows correlation between Nurses' Knowledge \& Performance. This table shows that statistical significant difference between Nurses' Knowledge \& Performance. $(\mathrm{P}<0.05)$

Table (5): shows correlation between Nurses' qualification and Nurses' Knowledge. This table shows that statistical significant difference between Nurses' qualification and Nurses' Knowledge. $(\mathrm{P}<0.03)$

Table (6): shows correlation between Years of experience at the I.C.U and Nurses' Knowledge this table shows that the statistical significant difference between Years of experience at the I.C.U and Nurses' Knowledge $(\mathrm{P}<0.02 *)$

Table (7): shows correlation between Nurses' qualification and Performance this table shows that statistical significant difference between Nurses' qualification and Performance. $(\mathrm{P}<0.038)$

Table (8): shows a correlation between Years of experience at the I.C.U and Performance this table shows that statistical significant difference between Years of experience at the I.C.U and Performance. $(\mathrm{P}<0.04 *)$

\section{Discussion}

One of the most common methods used to ensure patient safety in intensive care units (ICUs) is the use of physical restraints (Kandeel \& Attia 2013)

The aim of this study was to assess nurses' knowledge \& performance about physical restraints for critically ill patients.

Identified the key issues related to the knowledge base for nursing practice, both theoretical and evidence-based knowledge. This is the basic knowledge that every nurse should have to practice. Nurses use this knowledge base in collaboration with patients to assess, plan, implement, and evaluate care. (American Nurses Association. 2010)

Nurses spend more time with patients than do any other health care providers, and patient outcomes are affected by nursing care quality. Thus, improvements in patient safety can be achieved by improving nurse performance (DeLucia, Ott, \& Palmieri, 2009)

The results of the present study showed that more than half of the nurses were single, nearly half of the nurses were qualification of Bachelor sciences and half of them their years of experience in intensive care unit,low fifth years, this may attributed to policy assiut university hospital recruitment this group of nurses (single, newly graduated, B.Sc.) to deal with hard work of the critical care unit. (Ali \& Taha 2013) mention that mostly of the nurses were in middle age females with diploma degrees in nursing, they also mentioned that singles may spend more time in learning and studying compared with the married ones who have other responsibilities. This result disagree with(Ck Gan, , \& Sg Jesjeet, 2008). Who mentioned that only a fifth of the nurses in their study were married. This result agree with (FariñaLópez et al., 2014) One of the reasons that professionals in nurses also considered the application of restraint important was to avoid interference with treatments, particularly intravenous and feeding tubes who found no differences in the perceptions of restraint use between qualified nurses. This study agree with (Castle \& Engberg, 2009 \& Azab \& Negm, 2013).. Their findings were frequency of use of physical restraint decreased with increased nurses' qualifications

The findings revealed that all nurses had not attended any previous training courses about physical restraint. This study agreement with (Akansel 2007). Most of the ICU nurses $(95.2 \%)$ reported that they did not receive special education or any in-service training about physical restraint practices and nurses who reported receiving in service training about physical restraining practices were very few.Study agreed with (Ali \& Taha 2013). only eight of the nurses in the current study sample reported having information about physical restraining through training (Yeh et al. 2008). Mention that nurses' perception of restraint use had improved significantly after they had received the continuing education.

The current study revealed that the majority of the study sample $(70 \%)$ was having satisfactory level of knowledge in all items, this finding may attributed to nearly half of nurses had B.Sc. Nurses with higher qualification were better in knowledge than unqualified nurses. This study disagree with (Li \& Fawcett, 2014). Who stated that inadequate knowledge and clinical experience and biases would be inevitable. More seriously, the research showed that a large number of nurses used physical restraint without adequate assessment knowledge.(Li \& Fawcett, 2014). Not only should nurses receive more knowledge and skills preparation on the use of physical restraint, but also feasible alternatives or solutions need to be explored in order to help nurses.

At the same time, about $90 \%$ of the present studied sample had a satisfactory level of knowledge regard types of physical restraint This result agree with (Akansel, 2007 \& Chiba, \& Kawasaki, 2012). type of restraint use arm/leg belts or gloves. These restraints are usually placed to prevent accidents with drainages or catheters, and the use of these types of restraint maybe easily justified owing to medical reasons. Some techniques/skills provided by the staff to minimize restraints were associated with the use of arm/leg belts. these findings were in agreement with other research findings (Eşer* et al. 2007).who mention the most common type of restraint was 
bilateral wrist restraints.

Moreover the present study stated that $73.3 \%$ of the nurse had unsatisfactory Level of nurses Knowledge regarding items of barriers, this finding may attributed to no a written advice in patient record,fear from responsibility on occurrence of complication and there no legislation in the intensive care unit of physical restraint this result agree with (Saarnio \& Isola 2010). The single most significant factor making the nurse to unused of physical restraint type is the lack of legislation. (Fronczek Meg, 2014 \& Saarnio \& Isola, 2010) mention that The use of restraints caused feelings of guilt among the nursing staff, but on the other hand, it was seen as a way of making older patient feel more secure.

The current study revealed that more than half of nurses $(68.3 \%)$ had unsatisfactory level of Performance in all items. this finding may be attributed to There is no special training courses regarding physical restraint, the nurses often neglect updating their knowledge and performance in addition to lack library in intensive care unit and lack material of physical restraint. this present finding was agreed with (Al-Khaled et al., 2011). who mention that present study demonstrated that nurses' general knowledge regarding the practices of applying and maintaining physical restraining as well as their performance were moderate. This could be explained by the lack of training for nurses in physical restraining, the lack of written policies and procedures in ICUs guiding physical restraining and inadequate supervision and guidance by the nurse supervisors.

At same time it was found that $(100.0 \%)$ do not use any Nurses' Performance documentation before or after applying physical restraints on patients. Because of this insufficient practice, it is hard to say why patients are being physically restrained,

This result agree with (Eşer et al. 2007). (Sonya \& Negm, 2013). More than half of the respondent nurses $(52 \%)$ that they never record data for PR use in patient's chart (type of restraint used, indication for use, time of application and the related nursing care). Another study agreement with (Kandeel \& Attia 2013). was says Most nurses (98\%) reported that the of physical restraints was not documented in patient's medical records, this result agree with (Dergİsi, 2013 and Krüger et al., 2013). 90.6's\% of nurses' use of physical restraint did not record physical restraint.

The present study showed that there was statically significant difference between Nurses' Knowledge \& Nurses' Performance $(\mathrm{P}$-value $=0.05$ this result agree with (Al-Khaled et al., 2011) was found that there is a significant relationship between Nurses' Knowledge and nurses' performance. while this study disagree with (Luk et al. 2014)who stated The results demonstrated the lack of linkage between knowledge and clinical performance in this sample and call into question the supposition by many in nursing that knowledge and performance.

The study showed that there were statically significant differences between years' experience, qualification and nurses' knowledge, nurses' performance at the trauma intensive care unit (p-value $=0.02)(p$-value $=0.04)$ respectively, This can be explained by the fact that B.Sc. Nurses received some training on restraining while they were undergraduates as a procedure included in the nursing fundamental course. While, nurses graduated from the secondary nursing school did not receive any classes or clinical training on physical restraining. Nurses graduated from the technical institute of nursing received also training on restraining, although it is brief. this result agree with (Suchitra \& Lakshmi., 2007) who reported that; years of experience in the hospital significantly correlated to increased knowledge, attitudes and practices among the various categories of staff but this did not translate into good clinical practice in the ward. this result agree (Negm2 2013) experience in ICU. Who found more favorable attitude towards restraint application in the more experienced nurses. These findings were not in agreement with ( Hamers et al., 2009) (En \& Revista 2013) They found that, more experienced nursing staff had a more negative performance regarding restraints than other nursing staff.

This result agree with (Negm, 2013) who found highly educated staff was more prone to use restraints. Previous studies found that, changes in nurses' attitudes and practices might be influenced by the recent development of regulatory standards and nursing education related to restraint use in acute settings, and they varied a great deal in diverse clinical settings and across countries (Chien \& Lee 2007) Education of staff about physical restraint and the beneficial alternatives to restraint, together with the legal and ethical issues associated with this can reduce the use of restraint and will lead to an improved quality of life. (Lai \& Y, 2007).Education of staff about physical restraint and the beneficial alternatives to restraint, together with the legal and ethical issues associated with this can reduce the use of restraint and will lead to an improved quality of life.

\section{Conclusions}

Based on the results of the current study it can be concluded that the majority of the study sample $(70 \%)$ was having a satisfactory level of knowledge 
in all items, and more than half of nurses $(68.3 \%)$ had an unsatisfactory level of Performance in all items. There were statically significant differences between years' experience, qualification and nurses' knowledge, nurses' performance of the trauma intensive care unit.

\section{Recommendations}

Orientation programs should be utilized for nurses in the present study and newly jointed nurses to improve their related knowledge and practice, along with continuous supervision and feedback. Provide training programs to update critical care nurses' knowledge and performance about new physical restraint. Booklets about physical restraint should be available in each, unit of critical care unit using restraint in the hospital.

\section{References}

1. Akansel, N., (2007). Physical Restraint Practices Among Icu Nurses In One University Hospital In Weastern Turkey. Health Science Journal, (4). Available at: http://search.ebscohost.com/login.aspx?direct=tr ue $\&$ profile $=$ ehost $\&$ scope $=$ site $\&$ authtype $=$ crawle r\&jrnl=11087366\&AN=28691484\&h=aN9uHJy 4OD5fJyoUJ8N2SJgCJahyUBriC1x3cw91QFM S42JUJ5u4lIGcDR6QfHFUfa91/tvRI5aNL4sqS4 $\mathrm{ArfQ}==\& \mathrm{crl}=\mathrm{c}$ [Accessed March 31, 2014].

2. Ali, Z., \& Taha, N., (2013). Physical Restraints in Critical Care Units: Impact of a Training Program on Nurses' Knowledge and Practice and on Patients' Outcomes. Journal of Nursing \& Care, 02(02). Available at: http://www.omicsgroup.org/journals/physicalrestraints-in-critical-care-units-impact-oftraining-program-on-nurses-knowledge-andpractice-on-patients-outcomes-2167-1168-2135.php?aid=19504 [Accessed February 24, 2014].

3. Al-Khaled, T., Eman M., Zahran, A., \& ElSoussi, A., (2011). Nurses' related factors influencing the use of physical restraint in critical care units 1Tarek., 7(8), pp.13-22.

4. Azab, S., Negm, L., \& Negm2, S., \& L.A., (2013). Use of Physical Restraint in Intensive Care Units (ICUs) at Ain Shams University Hospitals, Cairo Sonya. , 9(4).

5. Bizek, K., (2010). The Patient's Experience With Critical Illness. In pp. 12-26.

6. Castle, N., \& Engberg, J., (2009). The health consequences of using physical restraints in nursing homes. Medical care, 47(11), pp.116473. Available at: http://www.ncbi.nlm.nih.gov/pubmed/19786918.
7. Chiba, Y., Yamamoto-Mitani Noriko \& Kawasaki Maki, (2012). A national survey of the use of physical restraint in long-term care hospitals in Japan. Journal of clinical nursing, 21(9-10), pp.1314-26. Available at: http://www.ncbi.nlm.nih.gov/pubmed/22300266 [Accessed October 3, 2014].

8. Ck Gan, St Jambunathan \& Sg Jesjeet, (2008). Pattern of the Use of Physical Restraint on Psychiatric Inpatients in University Malaya Medical Centre. , (8), pp.24-33.

9. Coyne, I., \& Scott, P., (2014). Alternatives to restraining children for clinical procedures. Nursing children and young people, 26(2), pp.22-7. Available at: http://www.ncbi.nlm.nih.gov/pubmed/24617890.

10. Demir, A., (2007). Nurses' use of physical restraints in four Turkish hospitals. Journal of nursing scholarship: an official publication of Sigma Theta Tau International Honor Society of Nursing / Sigma Theta Tau, 39(1), pp.38-45. Available at: http://www.ncbi.nlm.nih.gov/pubmed/17393964.

11. Dergİsí, G., (2013). Bir Üniversite Hastanesinde Çalışan Hemşirelerin Fiziksel Kısıtlamaya İlişkin Bilgi ve Uygulamaları. , pp.11-22.

12. DeLucia, P., Ott, T., \& Palmieri, P., (2009). Chapter 1 Performance in Nursing. Reviews of Human Factors and Ergonomics, 5(1), 1-40. doi:10.1518/155723409X448008

13. En, P., \& Revista, L., |(2013). Programa Desatar Al Anciano Y Al Enfermo De Alzheimer La tolerancia cero a las sujeciones puede ser una actitud de los profesionales que cuidan a las personas mayores. Es una actitud que se está extendiendo en España entre los profesionales de distintas, pp.1-26.

14. Eşer*, I., Khorshid, L., \& Hakverdioğlu Gülendam, (2007). The characteristics of physically restrained patients in intensive care units Yo $\breve{\mathrm{g}}$ un bak $1 \mathrm{~m}$ ünitelerinde fiziksel tespitli hastalar $1 \mathrm{n}$ özellikleri.

15. Facolt, B., et al., (2011). Use of physical restraints in adult ICU patients to prevent patient-initiated device removal: a systematic review Utilizzo della contenzione fisica nei pazienti adulti critici per prevenire 1 , autorimozione dei presidi : revisione sistematica della lett.

16. Fariña-López, E., et al., (2014). Perception of spanish nursing staff on the use of physical restraints. Journal of nursing scholarship: an official publication of Sigma Theta Tau International Honor Society of Nursing / Sigma Theta Tau, 46(5), pp.322-30. Available at: 
http://www.ncbi.nlm.nih.gov/pubmed/24754778 [Accessed September 21, 2014].

17. Fronczek Meg, (2014). Physical restraints : To use or not to use ? Q: When is the., (April), pp.54-55.

18. Gallagher, A., (2009). Ethical issues in patient restraint. Nursing times, 107(9), pp.18-20. Available at: http://www.ncbi.nlm.nih.gov/pubmed/21667649.

19. Gastmans, C., \& Milisen, K., (2006). Use of physical restraint in nursing homes: clinicalethical considerations. Journal of medical ethics, 32(3), pp.148-52. Available at: http://www.pubmedcentral.nih.gov/articlerender. fcgi? artid=2564468\&tool=pmcentrez\&rendertyp $\mathrm{e}=$ abstract [Accessed January 19, 2014].

20. Gulpers, M., et al., (2012). Preventing belt restraint use in newly admitted residents in nursing homes: a quasi-experimental study. International journal of nursing studies, 49(12), pp.1473-9. Available at: http://www.ncbi.nlm.nih.gov/pubmed/22917966 [Accessed February 4, 2014].

21. Hamers, J., \& Huizing, A., (2005). Why do we use physical restraints in the elderly? Zeitschrift für Gerontologie und Geriatrie, 38(1), pp.19-25. Available at: http://www.ncbi.nlm.nih.gov/pubmed/15756483 [Accessed March 21, 2014].

22. Hine, K., (2007). The use of physical restraint in critical care. Nursing in critical care, 12(1), pp.611. Available at: http://www.ncbi.nlm.nih.gov/pubmed/17883658.

23. Kandeel, N., \& Attia, A., (2013). Physical restraints practice in adult intensive care units in Egypt. Nursing \& health sciences, 15(1), pp.7985. Available at: http://www.ncbi.nlm.nih.gov/pubmed/23302019 [Accessed March 20, 2014].

24. Krüger, C., et al., (2013). Use of physical restraints in acute hospitals in Germany: a multicentre cross-sectional study. International journal of nursing studies, 50(12), pp.1599-606. Available http://www.ncbi.nlm.nih.gov/pubmed/23768409 [Accessed December 12, 2013].

25. Lai \& Y., C., (2007). Nurses using physical restraints: Are the accused also the victims? - A study using focus group interviews. BMC nursing, $6, \quad$ p.5. Available at: http://www.pubmedcentral.nih.gov/articlerender. fcgi?artid=1939996\&tool=pmcentrez\&rendertyp e $=$ abstract [Accessed October 3, 2014].

26. Li, X., \& Fawcett, T., (2014). Clinical decision making on the use of physical restraint in intensive care units. International Journal of
Nursing Sciences. Available at: http://www.sciencedirect.com/science/article/pii/ S2352013214000933 [Accessed October 17, 2014].

27. Lois White, Gena Duncan, W., (2011). Foundations of Basic Nursining third., Australia - Brazil - Japan - Korea • Mexico - Singapore • Spain - United Kingdom - United States: (C) 2001, 2005, 2011 Delmar Cengage Learning ALL. Available at: international.cengage.com/region.

28. Luk, E., et al., (2014). Predictors of physical restraint use in Canadian intensive care units. Critical care (London, England), 18(2), p.R46. Available http://www.pubmedcentral.nih.gov/articlerender. fcgi?artid=4075126\&tool=pmcentrez\&rendertyp $\mathrm{e}=$ abstract [Accessed October 3, 2014].

29. Milisen, K., (2009). Critical care nursing of older adults: best practices 3rd ed. F. Marquis D. Foreman, PhD, RN, FAAN Koen Milisen, PhD, RN Terry T. Fulmer, PhD, RN, ed., 11 West 42nd Street New York, NY 10036 www.springerpub. Available at: http://books.google.com/books?hl=en\&lr=\&id=F ckchBSqT0MC\&oi=fnd\&pg=PR5\&dq=Critical + Care+Nursing+of+Older+Adults+Best+Practices \&ots $=$ K4tqx $73 \mathrm{sHr} \&$ sig $=$ XSSeZNGnb8mAMLfR DqF540hrrZ4 [Accessed December 10, 2014].

30. Möhler, R., et al., (2012). Interventions for preventing and reducing the use of physical restraints in long-term geriatric care - a Cochrane review. Journal of clinical nursing, 21(21-22), pp.3070-81. Available at: http://www.ncbi.nlm.nih.gov/pubmed/22978254.

31. Ben Natan, M., et al., (2010). Physically restraining elder residents of long-term care facilities from a nurses' perspective. International journal of nursing practice, 16(5), pp.499-507. Available at: http://www.ncbi.nlm.nih.gov/pubmed/20854348 [Accessed March 28, 2014].

32. Negm2, S., \& L., (2013). Use of Physical Restraint in Intensive Care Units (ICUs) at Ain Shams University Hospitals, Cairo., 9(4).

33. Nettina, S., \& Msn, A., (2013). Lippincott manual of nursing practice 9th ed., Available at: WY 49 L765 2010] RT51.B78 2010 [Accessed September 26, 2014].

34. Pamela Lynn, (2011). Taylor's Handbook of Clinical Nursing Skills. Zhurnal Eksperimental'noi i Teoreticheskoi Fiziki. Available at: http://scholar.google.com/scholar?hl=en\&btnG= Search\&q=intitle:No+Title\#0 [Accessed September 27, 2014]. 
35. Saarnio, R., \& Isola, A., (2010). Nursing staff perceptions of the use of physical restraint in institutional care of older people in Finland. Journal of clinical nursing, 19(21-22), pp.3197207. Available at:

http://www.ncbi.nlm.nih.gov/pubmed/20726929 [Accessed May 27, 2014].

36. Sonya M., Azab \& Negm, L., (2013). Use of Physical Restraint in Intensive Care Units (ICUs) at Ain Shams University Hospitals, Cairo Sonya. , 9(4).

37. Yeh, S., et al., (2008). The effects of continuing education in restraint reduction on novice nurses in intensive care units. The journal of nursing research: JNR, 12(3), pp.246-56. Available at: http://www.ncbi.nlm.nih.gov/pubmed/15362016.

38. Yves Matillon, (2011). E Valuation Of Professional Practice In Healthcare Organisations Limiting The Risks Of Physical Restraint Of Elderly Subjects October 2000 Department of Evaluation in Healthcare Organisations, (October). 